\title{
Bazı Bitki Uçucu Yağlarının Armut Psillidi [Cacopsylla pyri (L.) (Hemiptera: Psyllidae)]'nin Kışlık-Formuna Karşı Yumurta Bırakmayı Engelleyici ve Ovisidal Etkileri
}

\author{
Barış iMREK ${ }^{1}$, Halil GÜVEN ${ }^{1}$, Fedai ERLER ${ }^{1^{*}}$, Hilal Şule TOSUN ${ }^{1}$ \\ ${ }^{1}$ Akdeniz Üniversitesi, Ziraat Fakültesi, Bitki Koruma Bölümü [ORCID ID: http://orcid.org/0000-0002-9917- \\ 0143 (B.IMREK), 0000-0002-5665-5968 (H. GÜVEN), 0000-0002-7216-9871 (F. ERLER), 0000-0001-8360-2610 (H.Ş. \\ TOSUN)] \\ 'Sorumlu yazar: erler@akdeniz.edu.tr
}

Öz

Armut psillidi, Cacopsylla pyri (L.) (Hemiptera: Psyllidae), Türkiye'de armut ağaçlarının en önemli zararlısı konumunda olup, mücadelesinde genelde sentetik kimyasal ilaçlar kullanılmaktadır. Son yıllarda bitkilerde doğal olarak bulunan bazı bileşiklerin sentetik pestisitlere alternatif olarak kullanılabilme olanaklarıyla ilgili çalışmalar önem kazanmış olup, bu çalışmada bazı bitkilerin (biberiye (Rosmarinus officinalis), nane (Mentha piperita), anason (Pimpinella anisum), rezene (Foeniculum vulgare), bergamot (Citrus bergamia) ve turunç (Citrus aurantium)) uçucu yağlarının zararlının kışlık-form erginlerine karşı yumurta bırakmayı engelleyici ve yumurtayı öldürücü etkileri laboratuvarda in vivo şartlarda araştıııımışırı. Her iki testte de, uçucu yağların tek dozu $\left(120 \mu \mathrm{I}^{-1}\right.$ su) kullanılmıştır. Uçucu yağların yumurta bırakmayı engelleyici etkileri iki haftalık bir ovipozisyon periyodu sonunda, ovisidal etkileri ise 10 günlük bir süre sonunda belirlenmiştir. Yumurta bırakmayı engelleyici etki testlerinden elde edilen sonuçlara göre, biberiye hariç tüm yağlar uygulamadan bir gün sonra yapılan sayımda $\% 100$ engelleyici etki göstermiştir. Turunç yağı, uygulamadan üç gün sonraki sayımda \%100 engelleme gösteren tek yağ olmuş, ancak bu etki 7, 10 ve 14 gün sonraki sayımlarda hızlı bir şekilde düşmüştür. Uçucu yağlardan rezene, tüm sayımlar boyunca en kalıcı etkiyi göstermiş olup, uygulamadan 10 gün sonraki sayımda bile $\% 50$ 'nin üzerinde engelleyici etki gösterebilen tek uçucu yağ olmuştur. Birinci günkü sayım dışında, nane yağı tüm sayımlarda en düşük engelleyici etkiye sahip yağ olmuştur. Ovisidal etki testlerinde ise, uygulamadan üç gün sonraki sayımda nane ve biberiye dışında tüm yağlar zararlının 0-48 saatlik yumurtalarında \%87.5-89.3 arasında değişen ölümlere neden olmuş, ancak 7 ve 10 gün sonraki sayımlarda tüm yağların etkinliği ani olarak düşmüştür. Tüm bu sonuçlar, söz konusu uçucu yağların armut psillidinin erken dönem mücadelesinde kimyasallara alternatif olabileceğini göstermiştir.

Anahtar Kelimeler: Armut psillidi, Cacopsylla pyri, Uçucu yağlar, Yumurta bırakmayı engelleyici etki, Yumurta öldürücü etki

\section{Oviposition Deterrent and Ovicidal Effects of Some Plant Essential Oils Against the Winter-Form of Pear Psylla, [Cacopsylla pyri (L.) (Hemiptera: Psyllidae)]}

\begin{abstract}
Pear psylla, Cacopsylla pyri (L.) (Hemiptera: Psyllidae) is the most important pest of pears in Turkey, and synthetic chemical insecticides are generally used in its control. In recent years, studies on the possibility of using some compounds naturally found in plants as an alternative to synthetic pesticides have gained importance, and in this study, oviposition deterrent and ovicidal effects of some plant essential oils (rosemary (Rosmarinus officinalis), mint (Mentha piperita), anise (Pimpinella anisum), fennel (Foeniculum vulgare), bergamot (Citrus bergamia) and bitter oranges (Citrus aurantium)) against winterform adults of the pest were investigated under in vivo conditions in the laboratory. In both tests, only one dose (120 $\mathrm{\mu l} \mathrm{I}^{-1}$ water) of each essential oil was used. The oviposition deterrent effects of essential oils were determined at the end of a 2-week oviposition period, while the ovicidal effects were
\end{abstract}


determined after a 10-day period. According to the results obtained from the oviposition deterrence tests, all the oils except rosemary showed a deterrence effect of $100 \%$ on the $1^{\text {st }}$ day after application. The citrus oil was the only oil that showed $100 \%$ oviposition deterrence three days after application, but this effect quickly decreased on the $7^{\text {th }}, 10^{\text {th }}$ and $14^{\text {th }}$ days after application. Out of all the essential oils tested, fennel showed the most stable effect during all the count times, and became the only essential oil showing an oviposition deterrent effect of over $50 \%$ even after 10 days later. Except the first day count, mint oil had the lowest deterrent effect at all the count times. In the ovicidal efficacy tests, all the oils except mint and rosemary caused mortalities ranging from 87.5 to $89.3 \%$ in the $0-48$ h-old eggs of the pest three days after application, but the activity of all the oils sharply decreased in the $7^{\text {th }}$ and $10^{\text {th }}$ day counts. Overall results showed that the essential oils in question may be alternatives to chemical insecticides in the control of pear psylla in early season.

Key Words: Pear psylla, Cacopsylla pyri, Essential oils, Oviposition deterrent effect, Ovicidal effect

\section{Giriş}

Armut, ülkemizde birçok yörede olduğu gibi Antalya-Korkuteli yöresinde de üretimi yapılan yumuşak çekirdekli meyveler içerisinde elmadan sonra ikinci sırayı almaktadır. Türkiye armut üretiminin yaklaşık \%20 kadarı, il genelindeki armut üretiminin de \%94'ü Korkuteli yöresinde üretilmektedir. Yaygın olarak üretilen çeşit 'Karyağdı' olup 'Coğrafi İşaretli Ürünler' arasına alınarak markalaştırılmıştır (TÜiK, 2015; Anonim, 2017).

Türkiye'nin armut üretilen diğer yörelerinde olduğu gibi, Antalya-Korkuteli yöresinde de armut yetiştiriciliğinin en önemli ve anahtar zararlısı Armut psillidi, Cacopsylla pyri (L.) (Hemiptera: Psyllidae)'dir (Kovancl ve ark., 2000; Erler, 2004a). Mücadele yapılmadığı yıllarda armutta önemli ekonomik kayıplar meydana getirebilmektedir. Armut psillidi; nimf ve erginlerinin bitki özsuyunu emerek yaptığı doğrudan zarar yanında, nimflerinin çıkardığı ballımsı madde ve üzerinde gelişen sekonder mantarlardan dolayı oluşan fumajin 'karaballık' zararı armut meyvesinin pazar değerini düşürmekte ve yaprakların fotosentez kabiliyetini azaltmaktadır. Zararlı ayrıca, armut göçüren (pear decline ya da Parry's disease) gibi çok önemli bazı armut hastalıklarının da taşıyıcısı (vektör) konumundadır (Julien, 1984; Staubli, 1984; Carraro, 1998).

Cacopsylla pyri mevsimsel olarak iki farklı ergin formuna sahiptir; daha iri, daha koyu renkli, kışlayan kışlık-form ve daha küçük, daha açık renkli ve daha fazla yumurta bırakma kabiliyetine sahip olan yazlıkformdur (Erler, 2004c). Yazlık-formlar, kışlıkform dişilerin bıraktıkları yumurtalardan meydana geldiğinden, kışık-form dişilerin henüz yumurta bırakmadan önce mücadele edilmesi ya da yumurta bırakmalarının engellenmesi zararlının tüm yıl boyunca bahçedeki popülasyonunun düşük seyretmesine neden olmaktadır. O yüzden, erken dönemde kışlık-form erginlerin hedef alınması, psillid mücadelesinde son derece önemlidir (Westigard ve Zwick, 1972).

Ülkemizin genelinde olduğu gibi, AntalyaKorkuteli yöresinde de zararlının mücadelesi genelde sentetik kimyasal ilaçlarla ve sezon boyunca 10-12 ilaçlama şeklinde yapılmaktadır. Kimyasal ilaçların bu denli yoğun kullanılması bazı problemleri de beraberinde getirmektedir. Bunlar; zararlı popülasyonlarında kimyasal ilaçlara karşı direnç gelişimi, ürünler üzerinde istenmeyen ilaç kalıntıları - ki bu da zaman zaman ihraç edilen ürünlerin geri dönmesine neden olmaktadır, hiç şüphesiz en önemlisi de çevre 
ve başta insanlar olmak üzere hedef dışı organizmalara toksik etkidir. Son 10-15 yıldır zararlının kimyasal mücadelesine alternatif olabilecek bazı uygulamalar yapılmış ve bunlardan olumlu sonuçlar alınmıştır (Erler, 2004b, 2004c; Erler ve Cetin, 2005; 2007; Erler ve ark., 2007; 2014). Bu çalışmada, kimyasallara alternatifler kapsamında üzerinde yoğun olarak çalışılan bazı bitkisel uçucu yağların $C$. pyri'nin kışlık-form dişilerine karşı yumurta bırakmayı engelleyici (oviposition deterrent) ve bu form dişilerince bırakılan yumurtalara karşı yumurta öldürücü (ovisidal) etkileri laboratuvarda in vivo şartlarda araştırılmıştır.

\section{Materyal ve Metot}

\section{Bitkisel Uçucu Yağlar}

Bu çalışmada, altı farklı bitki türünden elde edilmiş bitkisel uçucu yağların C. pyri'nin kışlık-form dişilerine karşı yumurta bırakmayı engelleyici etkileri ile bu form dişileri tarafından bırakılan yumurtalara karşı ovisidal etkileri araştırılmıştır (Çizelge 1). Söz konusu yağlar, yerel bir bitkisel uçucu yağ firması (Defne Doğa Şirketler Grubu, Bitkisel Yağlar ve Bitkisel Ürünler, Elmalı Mahl. Antalya)'ndan temin edilmiştir. Tüm yağlar saf olup, her bir uçucu yağın ön testlerde en etkin bulunan tek dozu (120 $\mu \mathrm{I}^{-1}$ su) kullanılmıştır. Distile su ve yağ karışımının sağlanabilmesi için, karışıma \%0.01'lik Tween-20 ilavesi yapılmıştır.

\section{Böcek Materyali}

Laboratuvarda yapılan biyolojik testlerde kullanılan zararlının kışlık-form erginleri Korkuteli ilçesi (Yazır köyü)'nden bir armut bahçesinden toplanmış ve 5 litrelik tül kapaklı plastik kaplarda laboratuvara getirilmiştir. Getirilen erginler hava sirkülasyonu bulunan pleksiglas kafeslerde testlerde kullanılıncaya kadar (2 gün süreyle) laboratuvar şartlarında $\left(23 \pm 2^{\circ} \mathrm{C}\right.$ sıcaklık ve $\% 45 \pm 10$ bağıl nem) taze armut sürgünleri üzerinde beslenmiştir.

Sürgünler, turgorlarının idamesi ve dolayısıyla canlı kalmaları için içi su dolu 0.5 litrelik plastik su şişelerine daldırılmış ve şişe ağızları pamuk ile kapatılarak erginlerin suya düşmeleri engellenmiştir.

Çizelge 1. Uçucu yağların elde edildiği bitkiler ve onlara dair spesifik bilgiler Table 1. The plants from which essential oils extracted and their specific information

\begin{tabular}{|c|c|c|c|}
\hline $\begin{array}{l}\text { Bitki adı } \\
\text { Plant name }\end{array}$ & $\begin{array}{l}\text { Bilimsel adı } \\
\text { Scientific name }\end{array}$ & $\begin{array}{l}\text { Familya } \\
\text { Family }\end{array}$ & $\begin{array}{l}\text { Uçucu yağın elde edildiği } \\
\text { bitki aksamı } \\
\text { Plant parts from which } \\
\text { essential oil extracted }\end{array}$ \\
\hline $\begin{array}{l}\text { Biberiye } \\
\text { Nane } \\
\text { Anason } \\
\text { Rezene } \\
\text { Bergamot } \\
\text { Turunç } \\
\end{array}$ & $\begin{array}{l}\text { Rosmarinus officinalis } \\
\text { Mentha piperita } \\
\text { Pimpinella anisum } \\
\text { Foeniculum vulgare } \\
\text { Citrus bergamia } \\
\text { Citrus aurantium } \\
\end{array}$ & $\begin{array}{l}\text { Lamiaceae } \\
\qquad " \\
\text { Apiaceae } \\
\quad " \\
\text { Rutaceae } \\
\quad "\end{array}$ & $\begin{array}{l}\text { Tüm toprak üstü aksam } \\
\text { Tüm toprak üstü aksam } \\
\text { Tohumlar } \\
\text { Tohumlar } \\
\text { Meyve kabuğu } \\
\text { Meyve kabuğu }\end{array}$ \\
\hline $\begin{array}{l}\text { Biyolojik Testler } \\
\text { Laboratuvar } \\
\text { ve } \% 45 \pm 10 \text { ba } \\
\text { bırakmayı engell } \\
\text { bitkisel uçucu y }\end{array}$ & $\begin{array}{l}\text { tlarında }\left(23 \pm 2{ }^{\circ} \mathrm{C} \text { sıcaklık }\right. \\
\text { nem) yapılan yumurta } \\
\text { ci etki testlerinde, seçilen } \\
\text { arın zararlının kışlık-form }\end{array}$ & $\begin{array}{l}\text { erginlerine karşı } \\
\text { engelleme etkisi ple } \\
75 \text { x } 75 \mathrm{~cm} \text {; } \\
\text { yürütülmüştür. Her } \\
\text { armut sürgünü (yap }\end{array}$ & $\begin{array}{l}\text { yumurta bırakmayı } \\
\text { eksiglas tül kafesler (100 x } \\
\text { boy x en x genişlik) } \\
\text { bir kafese, içerisinde üçer } \\
\text { raksız, dormant) bulunan }\end{array}$ \\
\hline
\end{tabular}


birer pet şişe konulmuştur. Her bir pet şişe içerisindeki yapraksız (dormant) sürgünler, seçilen bir uçucu yağın yukarıda belirtilen sulu konsantrasyonu (120 ml I-1 su) ile 0.5 litrelik basınçlı el tipi ilaçlama pompası (Chrysamed, Toprak Tarım, Antalya) kullanılarak iyice ıslanana kadar muamele edilmiş, muhtemel bir bulaşmayı önlemek için her bir uçucu yağ ile su-muameleli kontrol için ayrı pompalar kullanılmıştır. Uygulamadan sonra, her uçucu yağ ve sumuameleli sürgünler ayrı kafeslere konulmuş ve her bir kafese 20 adet yumurta olgunluğunu tamamlamış (abdomenleri kontrol edilerek seçilmiş) dişi birey salınmıştır. Kafeslerdeki sürgünler belirli aralarla (uygulamadan $1,3,7,10$ ve 14 gün sonra) stereo-mikroskop altında kontrol edilerek her bir muameledeki yumurta sayıları ayrı ayrı kaydedilmiştir.

Ovisidal etki testlerinde, bir önceki testlerde kullanılan yöntem aynen kullanılmış, ancak her bir kafes içerisindeki pet şişeye her biri üzerinde 0-48 saatlik 10'ar canlı yumurta bulunan üç adet dormant sürgün yerleştirilmiştir. Sürgünler, seçilen bir uçucu yağın $120 \mathrm{ml} \mathrm{I}^{-1}$ su dozuyla bir el pompası kullanılarak muamele edilmiş ve uygulamadan 3,7 ve 10 gün sonra yapılan kontrollerde her bir muameledeki ölü/canlı yumurta sayıları ayrı ayrı kaydedilmiştir. Streo-mikroskop altında yapılan sayımlarda, pörsümüş, çökmüş ve sonradan rengi kahverengi ve siyaha dönüşen yumurtalar ölü olarak kabul edilmiştir. Sayımlar sırasında bu yumurtalar, her sayım tarihi için farklı renkli keçeli bir kalemle işaretlenmiş ve son ölüm değerleri 10. gündeki sayımlar sırasında kaydedilmiştir.

Hem yumurta bırakmayı engelleyici etki hem de ovisidal etki testlerinde her muamele için üç tekerrür (kafes) kullanılmış olup, denemeler iki kez tekrarlanmıştır. Böylece her muamele için tekerrür sayısı 6 olmuştur. Kontrol sürgünleri her iki testte de distile su + \%0.01'lik Tween-20 karışımıyla muamele edilmiştir.

\section{Verilerin Değerlendirilmesi}

Yumurta bırakmayı engelleyici etki testlerinden elde edilen veriler varyans analizine tabi tutulmuş, $P=0.05$ önem seviyesinde muameleler arasındaki farklılıkların belirlenmesinde ise Duncan Çoklu Karşılaştırma Testi kullanılmıştır (SAS Institute, 2001). Ayrıca, her bir uçucu yağın yumurta bırakmayı engelleyici etkisi (oviposition deterrent index (o.d.i.) \%) aşağıdaki formül kullanılarak hesaplanmıştır;

$$
\text { o.d.i. }(\%)=(B-A) /(A+B) \times 100
$$

burada $A$ : muamele tarafındaki (uçucu yağ muameleli sürgünlerdeki) yumurta sayısı, B: ise kontrol tarafındaki (su-muameleli sürgünlerdeki) yumurta sayısıdır (Lundgren, 1975).

Ovisidal etki testlerinden elde edilen ölümler, Abbott (1925) formülü yardımıyla düzeltilmiş ölümlere çevrilmiştir. Muamelelerdeki ortalama ölüm oranları arasındaki farklılıkların istatistiksel olarak önemli olup olmadığı ise $P=0.05$ önem seviyesinde Duncan Çoklu Karşılaştırma Testi ile belirlenmiştir.

\section{Araştırma Bulguları ve Tartışma}

Yumurta bırakmayı engelleyici etki testlerinde, test edilen tüm uçucu yağlar zararlının kışık-form dişilerine karşı yumurta bırakmayı engelleyici etki göstermiştir (Çizelge 2). Bu etki, genelde uçucu yağa ve süreye göre değişmiştir. Kontrol ile karşılaştırıldığında, uçucu yağ muameleli sürgünlerde istatistiksel olarak önemli ölçüde daha düşük ovipozisyon meydana gelmiştir ( $F$ $=8.96 ; \mathrm{df}=1,8 ; P=0.05)$. Uygulamadan 1 
gün sonra yapılan sayımlarda kontrol ve biberiye uçucu yağıyla muameleli sürgünlerde yumurta görülürken, diğer tüm uçucu yağ muameleli sürgünlerde yumurtaya rastlanmamıştır. Üç gün sonraki sayımlarda, turunç hariç diğer tüm yağlarda ovipozisyon görülmüştür. Test edilen uçucu yağlar yumurta bırakmayı engelleme indeksleri bakımından karşılaştırıldığında, turunç yağı uygulamadan 1 ve 3 gün sonraki sayımlarda $\% 100$ 'lük bir yumurta bırakmayı engelleyici etki göstermesine rağmen sonraki sayımlarda rezene yağının gerisinde kalmıştır. Uçucu yağlar içerisinde en düşük indeks değerleri ise ilk (1 gün sonraki) sayım hariç nane uçucu yağında görülmüştür. Tüm sayımlardan elde edilen indeks değerleri dikkate alındığında, test edilen uçucu yağların armut psillidinin kışlık-form dişilerinin ovipozisyonunu engelleme bakımından en yüksekten en düşüğe sıralaması; rezene $>$ turunç $>$ anason $>$ bergamot $\geq$ biberiye $>$ nane şeklinde olmuştur.

Çizelge 2. Farklı uçucu yağ uygulamasından $3(u+3), 7(u+7), 10(u+10)$ ve $14(u+14)$ gün sonra Cacopsylla pyri'nin kışlık-form dişilerinin ovipozisyonu ve uçucu yağların yumurta bırakmayı engelleyici etkileri*

Table 2. Oviposition of winter-form females of Cacopsylla pyri $3(u+3), 7(u+7), 10(u+10)$ and $14(u+14)$ days after the application of different essential oil and oviposition deterrent effects of essential oils ${ }^{*}$

Uçucu yağ Kışlık-form dişiler tarafından bırakılan sürgün başına ortalama yumurta sayıları $( \pm \text { S.H. })^{\mathrm{xy}}$ ve Essential uçucu yağların yumurta bırakmayı engelleme indeksi (\%o.d.i.)

oil Mean no. $( \pm \text { S.E. })^{x y}$ of eggs per shoot laid by winter-form females and oviposition deterrent index (o.d.i.\%) of essential oils

\begin{tabular}{|c|c|c|c|c|c|c|c|c|c|c|}
\hline \multirow[b]{3}{*}{ Biberiye } & \multicolumn{2}{|c|}{$\mathrm{U}+1$} & \multicolumn{2}{|c|}{$\mathrm{U}+3$} & \multicolumn{2}{|l|}{$A+7$} & \multicolumn{2}{|c|}{$A+10$} & \multicolumn{2}{|l|}{$A+14$} \\
\hline & Ort. & \%o.d.i. & Ort. & \%o.d.i. & Ort. & \%o.d.i. & Ort. & \%o.d.i. & Ort. $\%$ & \%o.d.i. \\
\hline & $2.1 \pm 0.3^{\mathrm{Be}}$ & 87.5 & $4.7 \pm 1.3^{\mathrm{Cd}}$ & 69.4 & $6.8 \pm 3.2^{\mathrm{Cc}}$ & 43.2 & $10.7 \pm 3.1^{\mathrm{Bb}}$ & 27.2 & $16.3 \pm 4.3^{\mathrm{Da}}$ & $\begin{array}{ll} & 19.1\end{array}$ \\
\hline Nane & $0.0 \pm 0.0^{C d}$ & 100 & $8.8 \pm 2.2^{\mathrm{BC}}$ & 31.2 & $11.1 \pm 2.7^{\mathrm{Bb}}$ & 20.1 & $14.0 \pm 3.4^{\mathrm{Bb}}$ & b 12.7 & $31.2 \pm 4.4^{\mathrm{Ba}}$ & 5.9 \\
\hline Anason & $0.0 \pm 0.0^{C d}$ & 100 & $2.0 \pm 0.5^{\mathrm{Dc}}$ & 84.8 & $3.6 \pm 1.2^{\mathrm{ccb}}$ & 68.2 & $5.8 \pm 2.2^{\mathrm{Db}}$ & 46.4 & $17.9 \pm 2.3^{\mathrm{Da}}$ & 14.5 \\
\hline Rezene & $0.0 \pm 0.0^{\mathrm{Cd}}$ & 100 & $1.8 \pm 0.2^{\mathrm{Dc}}$ & 93.6 & $2.9 \pm 0.8^{D c}$ & 88.6 & $5.7 \pm 1.3^{\mathrm{Db}}$ & 53.4 & $8.1 \pm 2.4^{\mathrm{Ea}}$ & 38.8 \\
\hline Bergamot & $0.0 \pm 0.0^{\mathrm{Ce}}$ & 100 & $3.6 \pm 1.3^{\mathrm{Cd}}$ & 79.4 & $7.1 \pm 2.3^{\mathrm{Ccb}}$ & b 40.6 & $13.6 \pm 3.2^{\mathrm{Bb}}$ & b 22.3 & $28.2 \pm 4.8^{\mathrm{Ba}}$ & 7.6 \\
\hline Turunç & $0.0 \pm 0.0^{\mathrm{Cd}}$ & 100 & $0.0 \pm 0.0^{\mathrm{Ed}}$ & 100 & $4.9 \pm 0.9^{\mathrm{Cc}}$ & 72.9 & $7.4 \pm 2.2^{\mathrm{Cb}}$ & 46.9 & $22.3 \pm 3.6^{\mathrm{Ca}}$ & 12.8 \\
\hline Kontrol & $8.2 \pm 2.2^{\mathrm{Ae}}$ & - & $20.3 \pm 4.1^{A}$ & Ad - & $27.7 \pm 4.9^{A C}$ & Ac $\quad-$ & $46.4 \pm 5.2^{\mathrm{Ab}}$ & - & $63.8 \pm 5.6^{\mathrm{Aa}}$ & - \\
\hline
\end{tabular}

Ovisidal etki testlerinde, nane ve biberiye dışında test edilen diğer tüm uçucu yağlar zararlının kışlık-form ergin dişileri tarafından bırakılan 0-48 saatlik yumurtalarda uygulamadan 3 gün sonra yapılan sayımda \%87.5-89.3 arasında değişen ölümlere neden olmuşlardır (Çizelge 3). Nane ve biberiye uçucu yağları tarafından meydana getiren ölümler hem diğer uçucu yağlardan istatistiksel olarak daha düşük seviyede kalmış, hem de kendi aralarında ölüm değerleri bakımından istatistiksel bir fark görülmüştür $(F=6.308 ; \mathrm{df}=1,8 ; P=0.05)$. Uygulamadan 7 ve 10 gün sonra yapılan sayımlarda ise tüm uçucu yağların ovisidal etkisinde ani düşüşler görülmüştür.

Çalışma süresinse uçucu yağlar tarafından meydana getirilen her hangi bir fitotoksisiteye şahit olunmamıştır. Uygulamadan 3, 7, 10 ve 14 gün sonra yapılan gözlemlerde ne dormant (yapraksız) ne de sonradan açan sürgün tomurcuklarına 
hiçbir uçucu yağın fitotoksik bir etkisi saptanmamıştır.

Yapılan çalışmalar armut psillidinin kışlıkform erginlerinin ya yumurta bırakmadan önce öldürülmelerinin ya da hiç olmazsa ovipozisyonlarının engellenmesinin, armut bahçelerindeki o yılki psillid popülasyonlarının baskı altında tutulmasında son derece önemli olduğunu göstermiştir (Lyousoufi ve ark., 1988; Solomon ve Morgan, 1994; Erler ve Cetin, 2005, 2007).

Çizelge 3. Uygulamadan $3(U+3), 7(U+7)$ ve $10(U+10)$ gün sonra, uçucu yağların Cacopsylla pyri'nin kışlık-form dişilerinin bırakmış olduğu 0-48 saatlik yumurtalara karşı ovisidal etkileri $^{*}$

Table 3. Ovicidal effects of essential oils against the 0-48 $h$-old eggs laid by winter-form females of Cacopsylla pyri $3(U+3), 7(U+7)$ and $10(U+10)$ days after application*

\begin{tabular}{|c|c|c|c|}
\hline \multirow{2}{*}{$\begin{array}{l}\text { Uçucu yağ } \\
\text { Essential oil }\end{array}$} & \multicolumn{3}{|c|}{ Ortalama ölüm oranı (\%) $( \pm \text { S.H. })^{x y}$} \\
\hline & $U+3$ & $\mathrm{U}+7$ & $A+10$ \\
\hline Biberiye & $69.4 \pm 0.2^{\mathrm{Ba}}$ & $26.4 \pm 4.2^{\mathrm{cb}}$ & $6.8 \pm 2.2^{\mathrm{BC}}$ \\
\hline Nane & $53.8 \pm 0.2^{\mathrm{Ca}}$ & $27.8 \pm 3.4^{\mathrm{Cb}}$ & $3.7 \pm 1.3^{C c}$ \\
\hline Anason & $89.3 \pm 0.2^{\mathrm{Aa}}$ & $44.2 \pm 4.8^{\mathrm{Bb}}$ & $11.3 \pm 2.1^{\mathrm{Ac}}$ \\
\hline Rezene & $87.8 \pm 0.2^{\mathrm{Aa}}$ & $52.6 \pm 3.3^{\mathrm{Ab}}$ & $18.1 \pm 3.5^{\mathrm{Ac}}$ \\
\hline Bergamot & $88.7 \pm 0.2^{\mathrm{Aa}}$ & $18.5 \pm 3.3^{\mathrm{Db}}$ & $5.6 \pm 1.8^{\mathrm{BC}}$ \\
\hline Turunç & $87.5 \pm 0.2^{\mathrm{Aa}}$ & $23.6 \pm 4.2^{\mathrm{CDb}}$ & $4.8 \pm 2.2^{\mathrm{BCC}}$ \\
\hline
\end{tabular}

Bu çalışmadan elde edilen sonuçlar, bir kaçı dışında test edilen bitkisel uçucu yağların zararının kışlık-form ovipozisyonunu önemli ölçüde engelleyebildiğini ve ayrıca kışlık-form dişiler tarafından bırakılan yumurtalara karşı güçlü bir ovisidal etkiye sahip olduğunu göstermiştir.

Yapılan literatür taramasından elde edilen sonuçlar, ister mineral isterse bitkisel ve hayvansal kökenli olsun yağlı maddelerin armut psillidinin hem kışlık-form hem de yazlık-form ovipozisyonunu belli bir süreye kadar engelleyebildiğini göstermiştir. Örneğin, Erler (2004c) hem laboratuvar hem de arazi şartlarında yürüttüğü bir çalışmada bazı yağlı maddelerin (pamuk yağı, balık yağı, neem yağı ve yazlık yağ/beyaz yağ) C. pyri'nin kışlık-form ve yazlık-form dişilerinin ovipozisyonunu belli bir süre engelleyebildiğini tespit etmiştir. Bu etkinin, kışlık-form dişilerin ovipozisyonunu engelleme testlerinde yazlık yağ ve balık yağı için üç hafta boyunca \%100 olduğunu, ancak bitkisel yağlar olan neem ve pamuk yağı için ise sırasıyla bir ve iki hafta sürdüğünü bildirmiştir. Yağlı maddelerin armut psillidinin ovipozisyonunu engelleme etkisi Zwick ve Westigard (1978) tarafından da bildirilmiştir. $\mathrm{Bu}$ davranışsal etkinin mekanizmasına gelince, tarafımızdan yapılan gözlemler, zararlının kışlık-form erginlerinin yağlı yüzeyi değil yumurta bırakmak yerleşmek için dahi tercih etmediğini, hatta tarafımızdan bırakılan erginlerin yağlı yüzeyde yürüme zorluğu çektiğini göstermiştir.

Uçucu yağların, armut psillidinin kışlıkform ya da yazlık-form dişileri tarafından bırakılan yumurtalar üzerine ovisidal etkisi konusunda şuana kadar yapılmış her hangi bir çalışmaya rastlanamamıştır. Bu çalışma, bir kaçı hariç test edilen uçucu yağların kışlık- 
form dişiler tarafından bırakılan yumurtalar üzerine güçlü bir ovisidal etkiye sahip olduğunu göstermiş̧tir.

\section{Sonuçlar}

Bu çalışmadan elde edilen tüm sonuçlar, test edilen uçucu yağların erken dönemde armut psilldinin mücadelesine katkı sağlayabileceğini göstermiştir. Ileride bu zararlıya karşı armut bahçelerinde uygulanacak entegre mücadele (IPM) programlarında uçucu yağların, zararlının gerek ovipozisyonunu engelleyerek gerekse bırakılan yumurtalarını öldürerek önemli bir mücadele ögesi olabileceği açıktır. Ancak, bu konuda daha fazla çalışma yapılarak, uçucu yağların zararlının doğal düşmanlarına olumsuz bir etkisinin olup olmadığı araştırılmalıdır.

\section{Kaynaklar}

Anonim, 2017. Markalaştırılan Ürünler. http://www.haberler.com/karyagdiarmudu-cografi-isaretli-urunler-arasina7928668-haberi/. Erişim tarihi: 06.04.2017.

Abbott, W.S., 1925. A method for computing the effectiveness of an insecticide. Journal of Economic Entomology, 18: 265-267.

Carraro, L., 1998. Transmission of pear decline by using naturally infected Cacopsylla pyri $\mathrm{L}$. Acta Horticulturae, 472: 665-668.

Erler, F., 2004a. Natural enemies of the pear psylla Cacopsylla pyri in treated vs. untreated pear orchards in Antalya, Turkey. Phytoparasitica, 32(3): 295-304.

Erler, F., 2004b. Laboratory evaluation of a botanical natural product (AkseBio2) against the pear psylla Cacopsylla pyri. Phytoparasitica, 32(4): 351-356.

Erler, F., 2004c. Oviposition deterrency and deterrent stability of some oily substances against the pear psylla, Cacopsylla pyri. Phytoparasitica, 32(5): 479-485.

Erler, F., Cetin, H., 2005. Evaluation of some selective insecticides and their combinations with summer oil for the control of the pear psylla, Cacopsylla pyri. Phytoparasitica, 33(2): 169-176.

Erler, F., Cetin, H., 2007. Effect of kaolin particle film treatment on winterform oviposition of the pear psylla, Cacopsylla pyri. Phytoparasitica, 35(5): 466-473.

Erler, F., Yegen, O., Zeller, W., 2007. Field evaluation of a botanical natural product against the pear psylla (Homoptera: Psyllidae). Journal of Economic Entomology, 100(1): 66-71.

Erler, F., Pradier, T., Aciloglu, B., 2014. Field evaluation of an entomopathogenic fungus, Metarhizium brunneum strain F52, against pear psylla, Cacopsylla pyri. Pest Management Science, 70(3): 496-501.

Julien, J., 1984. The economic importance of pear psyllids for the production of pears in France. IOBC / WPRS Bulletin, 7(5): 7-12.

Kovancı, B., Gencer, N.S., Kaya, M., Akbudak, B., 2000. Uludağ Üniversitesi Ziraat Fakültesi armut bahçesinde Cacopsylla pyri (L.) (Homoptera: Psyllidae)'nin populasyon değiş̧imi üzerinde araştırmalar. Türkiye Entomoloji Dergisi, 24: 289-300.

Lundgren, L., 1975. Natural plant chemicals acting as oviposition deterrents on cabbage butterflies [Pieris brassicae (L.), P. rapae (L.) and P. napi (L.)]. Zoologica Scripta, 4: 253-258.

Lyousoufi, A., Rieux, R., D'Arcier, F.F., 1988. Evolution of the oviposition potential and number of eggs of the pear psylla Psylla pyri (L.) during the winter and spring period in the lower Rhone Valley. Journal of Applied Entomology, 106: 97-107.

SAS Institute, 2001. SAS/STAT User's Guide. Version 8.02. SAS Institute Inc., Cary, USA.

Solomon, M.G., Morgan, D., 1994. Timing pesticide applications in integrated pear

management: The role of modeling. IOBC / WPRS Bulletin, 17(2): 57-60.

Staubli, A., 1984. The economic importance of pear psyllids for the production of pears in Switzerland. IOBC / WPRS Bulletin, 7(5): 16-22.

Westigard, P.H., Zwick, R.W., 1972. The pear psylla in Oregon. The Oregon Agricultural Experiment Station Technical Bulletin, 122: 1-22.

Zwick, R.W., Westigard, P.H., 1978. Prebloom petroleum oil applications for delaying pear psylla (Homoptera: Psyllidae) oviposition. The Canadian Entomologist, 110: $225-23$ 